\title{
LA REGULACIÓN DE LOS CONTRATOS EN EL CÓDIGO CIVIL Y COMERCIAL
}

\section{REGULATION OF CONTRACTS IN THE CIVIL AND COMMERCIAL CODE}

\author{
FRANCISCO JUNYENT BAS \\ UNIVERSIDAD NACIONAL DE CÓRDOBA
}

ARGENTINA

MARÍA CONSTANZA GARZINO

UNIVERSIDAD NACIONAL DE CÓRDOBA

UNIVERSIDAD SIGLO 21

ARGENTINA

El derecho no es una pura teoría, sino una fuerza viva. Rudolf von Ihering. 


\section{SUMARIO}

I. Introducción. II. La nueva articulación contractual en el nuevo Código Civil y Comercial de Código Único. II.1. La teoría general del contrato. II. 2. La ubicación metodológica. III. El contrato discrecional o paritario. III. 1. La conceptualización amplia del contrato. III. 2. Autonomía de la voluntad y eficacia vinculante del contrato. III. 3. La clasificación general de los contratos. III. 4. El consentimiento: oferta y aceptación. IV. Los contratos por adhesión. IV. 1. La redacción unilateral de las cláusulas predispuestas. IV. 2. El modo de redacción de las cláusulas generales. IV. 3. Las cláusulas particulares. IV. 4. Las cláusulas abusivas. V. Los contratos de consumo. V. 1. La relación de consumo. V. 2. El contrato de consumo. V. 3. El concepto de consumidor. V. 4. El proveedor en los contratos de consumo. V. 5. Interpretación y prelación normativa: "in dubio pro consumidor". V. 6. El deber de información, la publicidad y trato digno. V. 7. La facultad de revocar el contrato. V. 8. Cláusulas abusivas. V. 9. Directivas de integración. VI. Conclusión.

\section{INTRODUCCIÓN}

El Código Civil y Comercial sancionado el 1 de octubre de 2014 y publicado en el Boletín Oficial el día 8 de octubre, produce importantes modificaciones en materia contractual, e intenta reflejar en la Teoría General del Contrato los cambios habidos en las relaciones en masa, sin dejar de reconocer la permanencia de las reglas fundantes del contrato, en orden a la libertad para contratar y la fuerza vinculante de la autonomía de la voluntad, pero agregando a éstas características las particularidades de las cláusulas predispuestas o los contratos formularios, disponiendo la tutela especial para evitar el abuso del predisponente.

En esta línea, resulta relevante entender los cambios producidos en la tipología contractual de manera tal de poder definir un primer concepto general que busca un "tipo mínimo", para luego articular los distintos contratos especiales.

De tal modo, el Código regla los contratos civiles y comerciales, aun cuando en su mayoría incorpora éstos últimos, delineando sus aspectos fundamentales.

Por último, no podía ignorarse la incorporación al código de fondo de la relación de consumo, es decir, de los contratos del sujeto que compra o adquiere bienes o servicios como destinatario final, o de quien se encuentra en su grupo familiar o social.

Todo este capítulo se incorpora en el Libro III, intentando mejorar las normas sobre el consentimiento, información y publicidad; eliminar o disminuir los desequilibrios y reforzar las obligaciones del proveedor. 


\section{LA ARTICULACIÓN CONTRACTUAL EN EL CÓDIGO CIVIL Y COMERCIAL}

\section{II.1. La teoría general del contrato}

Tal como lo enseña Stiglitz ${ }^{2}$ el Código Civil y Comercial introduce tres categorías de contratos, el denominado "paritario" del art. 957 al 983, el llamado "contrato de adhesión" o "por cláusulas generales predispuestas", arts. 984 a 989, y el "contrato de consumo" del art. 1092 a 1122.

Así, la nueva regulación de los contratos parte de una teoría general, que permite distinguir entre el contrato paritario, el de adhesión y el de consumo, los que forman parte de aquella, pero se caracterizan, ya sea por la igualdad en el poder de negociación de las partes, por el modo de redacción en formularios como son los predispuestos, y por último, por el acto de consumo que implica la debilidad estructural de los negocios en masa.

En definitiva, se ha modificado la regulación del contrato en la parte general, dividiéndola en las diversas modalidades referidas, todo lo cual implica una "tríada" que es necesario analizar para poder discernir su aplicación concreta a los contratos en particular.

Va de suyo, que en todos los casos previstos por la ley, resulta plenamente vigente el principio de buena fe, establecido en el art. 9 del nuevo Código, pues la ley no ampara el ejercicio abusivo de los derechos, tal como se desprende de los arts. 10 y 11, actualmente en el art. 1198.

En esta línea, Aparicio ${ }^{3}$ señala que el mandato de la buena fe no constituye un mero elemento de un supuesto de hecho normativo, sino que genera una norma jurídica completa que adquiere el rango de un principio general del derecho, y consecuentemente, todos los participantes del tráfico negocial deben comportarse de forma legal, proba y correcta en sus recíprocas relaciones, tanto en la génesis o formación del contrato, como después de su perfeccionamiento.

$\mathrm{El}$ autor citado enfatiza que el principio de buena fe enuncia los criterios que permiten colmar los vacíos susceptibles de generarse en la resolución de los casos concretos, planteados en la vida económica y social, permitiendo la función integradora derivada, secundaria y complementaria que debe operar dentro del marco del sistema.

\section{2. La ubicación metodológica}

Esta materia ha sido introducida en el Código en el Libro III, luego de la parte general relativa fundamentalmente a la persona humana y a los hechos y actos jurídicos, y al Libro II que aborda las relaciones de familia.

Por su parte, el Libro III trata los derechos personales, y en el Título II enfrenta la teoría general de los contratos, dividiéndola por capítulos que hacen a las disposiciones generales, a la clasificación de los contratos, a la formación del consentimiento, a las pautas de interpre-

2 STIGLITZ, Rubén, La teoría del contrato en el Código Civil y en el Proyecto de Código Civil y Comercial de la Nación, La Ley $13 / 06 / 2012$.

${ }^{3}$ APARICIO, Juan Manuel, Contratos en general, Observaciones al Proyecto de Código Civil y Comercial, La Ley, 5/12/2012, pág. 4. 
tación, a los contratos conexos, y a las obligaciones de saneamiento, como así también a la extinción, modificación y adecuación del contrato.

En la misma línea, dentro del Título II, se regulan los contratos celebrados por adhesión a cláusulas generales predispuestas, el Título III regla los contratos de consumo, y el Título IV los contratos en particular.

\section{EL CONTRATO DISCRECIONAL O PARITARIO}

\section{1. La conceptualización amplia del contrato}

En la temática de la nueva regulación se sigue similar criterio del Código de Vélez, que en el art. 1137 define el contrato, aspecto que hoy se encuentra en el art. 957, al señalar que el contrato es "el acto jurídico mediante el cual dos o más partes manifiestan su consentimiento para crear, regular, modificar, transferir o extinguir relaciones jurídicas patrimoniales".

En esta línea, Spota ${ }^{4}$ señala la utilidad de la conceptualización que suministra los elementos mediante los cuales es posible individualizar los aspectos fundantes que integran la relación contractual.

La nueva compilación adhiere al criterio de Mosset Iturraspe ${ }^{5}$ en el sentido de que el contenido del contrato es amplio pues, tiende a regular los derechos patrimoniales, obligacionales o reales, excluyendo sólo a los acuerdos que no tienen por objeto una relación de derecho.

Así, Aparicio ${ }^{6}$ explica que la fuente de dicha norma es el artículo 1321 del Código Civil italiano, seguido por el art. 1351 del Código Civil peruano, y por el art. 7 de las Propuestas para una Reforma del Derecho de Contrato, elaborada por un grupo de trabajo bajo la dirección de Francois Terré, en el año 2009.

\section{2. Autonomía de la voluntad y eficacia vinculante del contrato}

En este sentido, en el art. 958 se puntualiza que "las partes son libres para celebrar un contrato y determinar su contenido, dentro de los límites impuestos por la ley, el orden público, la moral y las buenas costumbres", de manera tal, que se mantiene la vigencia del principio de autonomía de la voluntad, que le otorga fuerza obligatoria a la convención, tal como sucede actualmente por imperio del art. 1197 del Código Civil.

En consecuencia, el art. 959 del Código Civil y Comercial establece que todo contrato válidamente celebrado es obligatorio para las partes, y su contenido sólo puede ser modificado o extinguido por acuerdo de partes o en los supuestos que la ley prevé.

\footnotetext{
${ }^{4}$ SPOTA, Alberto, Instituciones de Derecho Civil, Contratos, Depalma, Buenos Aires, 1996, vol. 1, pág. 2.

${ }^{5}$ MOSSET ITURRASPE, Jorge, Contratos, Rubinzal Culzoni, Santa Fe, 1995.

${ }^{6}$ APARICIO, Juan Manuel, Contratos en general, Observaciones al Código Civil y Comercialde Código, La Ley, 5/12/2012, pág. 2.
} 
En igual línea de pensamiento, el art. 960 dispone que los jueces no tienen facultad para modificar las estipulaciones de los contratos, excepto que sea a pedido de una de las partes, cuando lo autoriza la ley, o de oficio, cuando se afecta de modo manifiesto el orden público.

De tal modo, Gastaldi y Gastaldi señalaron que los pilares fundamentales de la noción de contrato en el Código Civil y Comercial son: la autonomía de la voluntad, la fuerza obligatoria de los contratos, todo lo que se enmarca en el principio de la buena fe. Que también tiene sus limitaciones en las normas indisponibles, la moral, las buenas costumbres y el orden público.

Sin embargo, la teoría clásica de la autonomía de la voluntad que confiere a la palabra empeñada en los contratos fuerza obligatoria semejante a la de la ley ha sido debilitada por la civilización jurídica, no sólo para compensar los desequilibrios generados en la contratación en masa, sino también, para tutelar a la parte débil, y de allí, los denominados contratos con cláusulas predispuestas y el contrato de consumo.

En la actualidad, enseña Farina que el contrato del siglo XXI será el que celebre la empresa monopólica, de hecho y de derecho, con el consumidor individual, y ello presupone precisamente la eliminación de todo margen a la ya escasa libertad contractual, pues al consumidor, también le será sustraída su posibilidad de seleccionar libremente a su contratante.

De todas formas, es razonable que la nueva regulación haya establecido y regulado las disposiciones generales aplicables a todos los contratos, y específicamente, reconocido la autonomía de la voluntad, la libertad para contratar y la fuerza vinculante de la convención.

\section{3. La clasificación general de los contratos}

Desde esta perspectiva, el ordenamiento clasifica a los contratos en los art. 966 a 970, como unilaterales y bilaterales, a título oneroso y a título gratuito, conmutativos y aleatorios, formales, nominados e innominados.

Así, el clásico contrato "bilateral" es aquél en el cual las partes se obligan recíprocamente la una hacia la otra, y cuyas normas se aplican supletoriamente a los contratos plurilaterales, mientras que el denominado "unilateral" significa que la obligación pesa sobre una de las partes.

Por su parte, la clasificación de contratos a título "oneroso" o "gratuito", hace a las ventajas que procuran las partes y se modalizan como "conmutativos" o "aleatorios", cuando las aludidas ventajas están regladas para todos los contratantes o en el segundo caso, cuando dependen de un acontecimiento incierto.

En orden a la clasificación de los contratos formales, se mantiene el principio de la libertad de formas, tal como lo establece el art. 969, cuando señala que: "si la ley o las partes no imponen una forma determinada ésta constituye sólo un medio de prueba de la celebración del contrato".

En igual línea, la forma requerida para los contratos implica que la solemnidad es requerida para que éstos produzcan sus efectos propios, y no quedan concluidos como tales 
mientras no se haya otorgado el instrumento previsto, pero valen como contratos en los que las partes se obligaron a cumplir con la expresada solemnidad, tal como lo manda el art. 969.

Por último, la ley reconoce que la caracterización de los contratos "nominados" e "innominados" depende de que se encuentran o no regulados específicamente en la ley, tal como se desprende del art. 970, estipulando que los innominados se rigen por la voluntad de las partes, por las normas generales sobre contratos, por los usos y prácticas del lugar de celebración, y específicamente por las disposiciones correspondientes a los contratos nominados compatibles con su finalidad.

\section{4. El consentimiento: oferta y aceptación}

En esta inteligencia, la nueva compilación regula el perfeccionamiento del contrato, es decir, al consentimiento, oferta y aceptación, sigue a la teoría clásica de la recepción, tal como lo señala de manera expresa en el art. 971: "los contratos se concluyen con la recepción de la aceptación de la oferta o por una conducta de las partes que sea suficiente para demostrar la existencia de un contrato".

En opinión de Aparicio9, esta redacción coincide sustancialmente con los que utiliza el art. 2.1 de los Principios de Unidroit donde se atribuye a la conducta de las partes gran importancia, en especial, en la práctica de la contratación mercantil, pues en estos casos los contratos se celebran después de prolongadas negociaciones, sin que sea posible muchas veces identificar las secuencias de oferta y aceptación, y en estos supuestos el comportamiento puede ser trascendente para demostrar el acuerdo.

Por su parte, el proyectado art. 972 establece que la oferta es la manifestación dirigida a persona determinada o determinable, con la intención de obligarse y con las precisiones necesarias para establecer los efectos que debe producir de ser aceptada.

En esta línea, Aparicio ${ }^{10}$ critica la fórmula utilizada entendiendo que no refiere a los elementos esenciales como lo hace el art. 1148 del Código Civil. En igual sentido, expresa que el Proyecto, de manera más flexible, habilita que la oferta sea a persona determinada o determinable, lo que se vincula con la validez de la oferta hecha al público.

En esta línea, Gastaldi y Gastaldi ${ }^{11}$ señalan que la oferta dirigida a personas indeterminadas debe ser considerada como una invitación a oír ofertas, criterio que expone la Convención de Viena, art. 14.2, y sobre el que eran contestes doctrina y jurisprudencia, excepto que de sus términos o de las circunstancias de la emisión resulta la intención de contratar del oferente. En este caso se la entiende emitida por el tiempo y en las condiciones admitidas por los usos. 
A su vez, el art. 974 establece la fuerza obligatoria de la oferta y el art. 978 indica que la aceptación perfecciona el contrato cuando es recibida por el proponente durante el plazo de vigencia de la oferta.

En igual sentido, Aparicio ${ }^{12}$ coincide que el Código Civil y Comercial atribuye fuerza obligatoria a la oferta, y que como ha sido siempre, cabe distinguir dos modalidades de contratación: entre presentes y entre ausentes.

En relación a esta segunda modalidad, el autor citado reconoce que el proponente queda obligado al momento de la recepción, aspecto que también se vincula al plazo de duración, y que sin embargo, la reformulación de la nueva compilación sólo hace referencia a la inexistencia de plazo.

Por su parte, el art. 980 puntualmente indica las oportunidades del perfeccionamiento expresando que si el contrato es entre presentes, la aceptación es la que lo configura, y en el caso de que sea entre ausentes, la concreción del negocio se produce cuando la aceptación es recibida por el proponente dentro del plazo de vigencia de la oferta, con lo que queda expresamente determinado el momento a partir del cual el contrato comienza a producir efectos. Además, esta regulación brinda seguridad jurídica a los fines de la determinación de la competencia y del derecho aplicable.

En esta inteligencia, Aparicio ${ }^{13}$ destaca que el sistema de recepción para la formación del contrato entre ausentes se lleva a cabo a través de declaraciones, que son recepticias, es decir, dirigidas a una persona porque están destinadas precisamente a comunicarles una voluntad, y razonablemente, deben producir efectos cuando cumplen con su destino natural y son recibidas por el destinatario.

Por último, el art. 983 define la recepción al disponer que "la manifestación de una parte es recibida por otra cuando ésta la conoce o debió conocerla, trátese de comunicación verbal, de recepción en su domicilio de un instrumento pertinente o de otro modo útil", lo que resulta notoriamente contradictorio con la expresa asunción de la teoría de la recepción que se adopta en el Código.

La aceptación de la teoría de la recepción no es cuestionada por Aparicio ${ }^{14}$, quien señala que pese al texto legal, nuevamente se insiste en que la manifestación de voluntad es recibida por la otra cuando ésta "la conoce o debió conocerla" introduciéndose nuevamente en un aspecto contradictorio, pues la recepción es un estadio anterior a dicho conocimiento.

En efecto, si el destinatario conoce la comunicación, obviamente es porque la recibió, y tal recepción tan sólo basta para que la declaración surta efectos.

Por su parte, Gastaldi y Gastaldi ${ }^{15}$ admiten también que se ha seguido la teoría de la re-

\footnotetext{
${ }^{12}$ APARICIO, J.M, ob. cit., pág. 9.

${ }^{13}$ APARICIO, J.M, ob. cit., pág.15.

${ }^{14}$ APARICIO, J.M, ob. cit., pág.16.

${ }^{15}$ GASTALDI; GASTALDI, ob. cit., pág. 15.
} 
cepción, pero insisten que siempre será necesario sobre la cuestión del plazo de vigencia de la oferta, afirmando que si hay plazo habrá que atenerse a él, y si no lo hay, según sea oferta a persona determinada o determinable, hasta el momento en que pueda razonablemente esperar la recepción de la oferta.

En definitiva, cabe destacar que lo distintivo de esta categoría deviene de que la ley presupone la igualdad entre las partes en todo lo relativo a la negociación del contrato, y en consecuencia, regula los requisitos y efectos de éste.

\section{LOS CONTRATOS POR ADHESIÓN}

\section{1. La redacción unilateral de las cláusulas predispuestas}

Desde otro costado, también se reglan los acuerdos con cláusulas predispuestas, es decir, aquellos mediante el cual uno de los contratantes adhiere a cláusulas generales predispuestas, tal como lo establece el art. 984, estipulándose sus características en los art. 985 a 989.

En este sentido, el artículo 984 define este tipo contractual como aquél: "mediante el cual uno de los contratantes adhiere a cláusulas generales predispuestas unilateralmente, por la otra parte o por un tercero, sin que el adherente haya participado en su redacción".

Tal como resulta de la lectura de la disposición, al referirse a esta modalidad, el Código Civil y Comercial alude a "contrato", por lo que suprime todo debate en torno a la naturaleza jurídica de su contenido, o sea, de las cláusulas predispuestas, en atención a que lo que caracteriza este tipo de relación es justamente que su redacción lo hace la parte "fuerte" que deviene en predisponente, y la contraparte simplemente adhiere, aún cuando pueden negociarse algunas cláusulas particulares.

En una palabra, se desprende de la definición, la existencia de dos partes: por un lado el predisponente que es quien redacta el documento contractual o se sirve de la redacción efectuada por un tercero. Por otro lado, el adherente que no sólo no ha participado en la creación del texto contractual, sino que, tampoco, ha influido en su contenido.

Va de suyo, que éste tipo de relaciones se dará en la mayoría de los casos en el quehacer mercantil donde la parte predisponente impone sus condiciones, aún cuando la ley habilita la negociación de cláusulas particulares y regula especialmente las cláusulas abusivas en el art. 988, estableciendo la facultad judicial de declarar la nulidad parcial del contrato e integrarlo.

\section{2. El modo de redacción de las cláusulas generales}

El nuevo Código en el art. 985 exige que las cláusulas generales tengan una redacción clara, completa y fácilmente inteligible, prohibiendo el reenvío a otros textos y tornando aplicable 
este dispositivo a las contrataciones telefónicas o electrónicas o similares.

Así, cabe recordar que tal como lo enseña Farina ${ }^{16}$ las condiciones generales al estar destinadas a su reiterada aplicación, son concebidas para no agotar su función con la inserción en un contrato determinado, y por ello, son declaraciones dirigidas al público, sin relación con un sujeto individualizado, de donde generalidad equivale a uniformidad, o sea, fijeza de su contenido.

En esta línea, tal como señala Stiglitz ${ }^{17}$ : "el Código Civil y Comercial hizo prevalecer la importancia de la legibilidad, la inteligibilidad y la completividad de la cláusula de modo que para la comprensión de su lectura se haga innecesario un reenvío a otra cláusula. Sobre el particular cabe señalar y repetir que a la claridad se une la legibilidad para que las cláusulas predispuestas que contienen restricciones dirigidas al adherente no pasen inadvertidas y, para ello, deben aparecer destacadas del resto del documento contractual".

En una palabra, se ha enfatizado en la necesidad de un conocimiento pleno y cabal del texto contractual por parte del adherente, al punto que se declara como no convenidas las cláusulas que contengan reenvíos a textos que no se le faciliten previamente, atento a que éste tipo de prácticas no respeta el deber de información necesario para una manifestación de la voluntad no viciada.

\section{3. Las cláusulas particulares}

Asimismo, el art. 986 regla las cláusulas particulares como aquellas que negociadas individualmente, amplían, limitan, suprimen o interpretan una cláusula general, y por ende, prevalecen sobre éstas.

De tal modo, el art. 987 dispone como pauta de interpretación relevante que las cláusulas ambiguas predispuestas se interpretan en sentido contrario al predisponerte.

En igual sentido, Stiglitz ${ }^{18}$ destaca que: "la disposición, además de definir el significado de la "cláusula particular", incorpora una regla de interpretación proficua en su aplicación por los Tribunales y que tiene su fundamento en la preferencia que se otorga a la cláusula negociada en tanto constituye el resultado de la libre contratación por sobre la cláusula general, resultado de la predisposición contractual".

En esta inteligencia, surge como directiva de la nueva regulación que en caso de discrepancia entre una cláusula general y otra particular, prevalecerá esta última, receptando el clásico principio interpretativo en materia contractual.

El criterio es claro, en cuanto la cláusula negociada tiende a alterar, suprimir o aclarar el contenido de la general, otorgándole un contenido más específico adaptado al caso concreto.

\footnotetext{
${ }^{16}$ FARINA, J. M., Contratos comerciales modernos, ob. cit., pág. 87.

${ }^{17}$ STIGLITZ, R., ob. cit.

${ }^{18}$ STIGLITZ, R., ob. cit.
} 
De tal modo, el intérprete no debe perder de vista que la cláusula negociada o agregada, se estipula al tiempo de la conclusión del contrato, mientras que la cláusula predispuesta general se encuentra redactada previamente por el predisponente sin consideración al negocio concreto, por lo cual cabe concluir que la regla de autonomía particularmente concertada revela la auténtica intención de las partes.

\section{4. Las cláusulas abusivas}

Desde otro costado, el art. 988 considera como abusivas aquellas cláusulas que: a) desnaturalizan las obligaciones del predisponente y, aunque la ley no lo diga, también las del adherente; b) las que importen renuncia o restricción de derechos del adherente; y c) las que por su contenido o redacción o presentación no son razonablemente previsibles.

Por su parte, el art. 989 regula el control judicial de las cláusulas abusivas, sea por vía administrativa, sea por vía judicial, subrayando que éste último se puede ejercer aún cuando se haya utilizado la vía administrativa, y que en su caso, el juez declara la nulidad parcial del contrato, otorgándole la facultad de integrarlo.

En este sentido, Stiglitz ${ }^{19}$ explica que "la expresión desnaturalización de la relación a la que se halla obligado el predisponente refiere a tres hipótesis:

(a) ampliando los derechos del proveedor/profesional con daño al consumidor;

(b) modificando, en su favor y en algún sentido, la obligación a la que se ha comprometido el proveedor/profesional;

(c) ampliando las obligaciones del consumidor o restringiendo o suprimiendo sus derechos".

De tal modo, este tipo de cláusulas deviene del texto del art. 37 de la Ley de Defensa del Consumidor, y en este sentido, la regulación es también aplicable al contrato de consumo, tal como puntualmente lo señala el art. 1117.

A su vez, el art. 1118 establece el control de incorporación de las cláusulas abusivas, remitiendo a los arts. 985/986/988 del Proyecto.

En este sentido, Stiglitz dice que: "La disposición precedente, importa un control de incorporación al contrato y, tal vez, constituya un logro sin precedentes desde la perspectiva de las normas de protección al consumidor. No se nos oculta, la influencia que tuvo en el Proyecto, la redacción dotada al artículo 3 de la Directiva 93-13 de la CEE (hoy U.E.) y que fuera recogida por los veintisiete países miembros. A pesar de haber identificado la fuente, creemos que el Código Civil y Comercial ha ido más allá de ésta a través de una disposición muy clara, contundente y más breve, sin remitir a la necesidad de efectuar ningún tipo de apreciación global que induzca al intérprete a suponer que se halla frente a un contrato por adhesión".

El artículo 1118 del Código Civil y se aplica a los contratos de consumo y, también, a los contratos por adhesión por establecerlo así el artículo 1117.

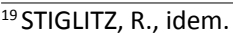


En definitiva, vale la pena destacar que este tipo de contrato será el que normalmente se configura en las redes de comercialización, y consecuentemente, constituirán en su enorme mayoría materia comercial.

\section{LOS CONTRATOS DE CONSUMO}

\section{1. La relación de consumo}

Desde otro costado, la sección comienza adecuadamente definiendo un ámbito mas amplio como lo es la "relación de consumo" para luego introducirse en la conceptualización específica del "contrato de consumo" expresando en el art. 1093 que son aquellos en donde el consumidor, adquiere bienes y servicios de personas físicas o jurídicas que actúan como profesionales en el mercado, de manera tal que la citada adquisición se hace para destino final y/o para su uso privado familiar y social.

En esta línea, se advierte que la conceptualización del consumidor es similar a la contenida en el art. 1 de la ley especial, aún cuando se elimina la figura incorporada por la ley 26.361 referida al sujeto expuesto a una relación de consumo o "bystander", bajo el velo de acotar una legitimación que se considera extremadamente amplia, tal como analizaremos infra.

En esta inteligencia, resulta patente que el criterio del "contrato de consumo" se encuentra inmerso en el concepto más amplio de la "relación de consumo", respetando así la jerarquía constitucional del derecho del consumidor, que emana del art. 42 de la Carta Magna, y dejando a salvo también la legislación especial pautada en la ley 24.240 y sus modificaciones.

Los derechos del consumidor son una especie del género "derechos humanos" y por ello, un principio basilar en la materia es el de asegurar a este sujeto el acceso a la justicia de manera fácil y eficaz, lo que cual debe entenderse inclusive como una exigencia de orden público.

\section{2. El contrato de consumo}

Tal como explica Aída Kemelmajer de Carlucci ${ }^{20}$, el contrato de consumo no es un tipo especial más, sino una fragmentación del tipo general de los contratos, que influye sobre los tipos especiales, es decir, compraventa de consumo, etc. y de allí, la necesidad de incorporar su regulación en la parte general.

En esta línea, los autores del Proyecto, al fundamentar su inclusión en el Código de fondo sostienen que en el derecho comparado hay distintos modelos, al reglar los contratos civiles y los comerciales, y en especial al considerar el contrato de consumo.

Así, expresan que una alternativa es la de mantener las regulaciones separadas, y en esta

\footnotetext{
${ }^{20}$ KEMELMAJER de CARLUCCI, Aída, Conferencia dictada en la Carrera de Negocios de la UNC, 28/7/12.
} 
línea, se puede citar el criterio del Código de Consumo italiana ${ }^{21}$; el de la legislación complementaria española ${ }^{22}$; y el ante Código Civil y Comercial de Reforma del Código Civil francés, que también mantiene la independencia del régimen consumeril.

Por el contrario, la reforma del año 2002 al Código Civil alemán incorporó algunas normas aplicables específicamente al derecho del consumidor, junto con otras propias de las condiciones generales de contratación. En igual sentido, el Código Civil de Québec de 1991 también incluyó disposiciones atinentes a los contratos de consumo, y a los celebrados por adhesión, y también puede citarse el Código Civil holandés dentro de esta corriente.

En Latinoamérica, los Estados parte del Mercosur, Brasil, Paraguay, Uruguay y Venezuela, como los Estados Asociados Bolivia, Chile, Perú y Colombia, tienen leyes separadas del Código Civil.

De tal modo, la reformulación que realiza el Código Civil y Comercial argentino parte del reconocimiento de que los derechos del consumidor tienen rango constitucional, y consecuentemente, la unificación de los contratos civiles y comerciales requiere incorporar también a la relación de consumo, y a éste contrato, en el código de fondo asegurando los aspectos fundantes de la tutela del consumidor.

La jurista citada entiende que la solución es consistente con la Constitución Nacional, que considera al consumidor como un sujeto de derechos fundamentales, respetando también la legislación especial pautada en la ley 24.240.

En esta línea, del funcionamiento de la tríada contractual, Kemelmajer explica que el sistema funciona de la siguiente manera: "cuando hay un contrato discrecional, debe existir plena autonomía privada e igualdad de las partes; por el contrario, cuando se está frente a un contrato por adhesión hay una tutela basada en la aplicación de este régimen; y por último, en cuanto al contrato de consumo, ya no interesa si hay o no adhesión, sino que hay que estar a los elementos típicos del art. 1092.

\section{3. El concepto de consumidor}

Desde esta perspectiva, el proyectado art. 1092 del nuevo Código señala que "relación de consumo es el vínculo jurídico entre un proveedor y un consumidor. Se considera consumidor a la persona física o jurídica que adquiere o utiliza en forma gratuita u onerosa, bienes o servicios como destinatario final, en beneficio propio o de su grupo social".

Asimismo agrega que "queda equiparado al consumidor quien, sin ser parte de una relación de consumo, como consecuencia o en ocasión de ella adquiere o utiliza bienes o servicios como destinatario final, en beneficio propio o de su grupo familiar o social".

\footnotetext{
${ }^{21}$ Decreto legislativo $N^{\circ} 206,6$ de septiembre de 2005.

${ }^{22}$ Real Decreto legislativo 1/2007, del 16 de noviembre de 2007.
} 
En esta inteligencia, la normativa fondal reconoce al consumidor directo, es decir, a quien contrata efectivamente para su destino final, es decir, cerrando el círculo económico, así como al indirecto, entendiéndose por tal a la persona que utiliza un bien o servicio como destinatario final por encontrarse dentro del grupo familiar o social del adquirente.

Sin embargo, pareciera que se ha eliminado al consumidor "expuesto" a una relación de consumo que se encuentra amparado en el último párrafo del art. 1 de la ley 24.240, según texto de la ley 26.361.

En esta línea, el Código sólo lo incorpora en el art. 1096 cuando se reglan las prácticas abusivas y se establece en al art. 1097 que los proveedores deben asegurar un trato digno a los consumidores y usuarios y, consecuentemente, deben abstenerse de desplegar conductas que coloquen a los consumidores en situaciones vergonzantes, vejatorias o intimidatorios.

Desde otro punto de vista, la Comisión redactora había excluido del concepto de consumidor a aquellos casos en que la compra tenía vinculación con la actividad comercial, industrial, artesanal o profesional del adquirente o usuario. Sin embargo, el Poder Ejecutivo eliminó dicho párrafo.

En esta línea, Stiglitz ${ }^{23}$ criticó la modificación efectuada por el Poder Ejecutivo que elimina la exclusión pautada por la comisión y considera que debe mantenerse el texto originario.

Desde nuestra perspectiva, la crítica del conocido jurista carece de fundamento dado el alcance del acto de consumo, que al cerrar al circuito económico no permite su integración a una actividad comercial o industrial.

Por su parte, el texto construido por el Poder Ejecutivo no advierte que toda adquisición que no tenga destino final excluye al adquirente de la figura del consumidor a tenor de la propia caracterización pautada en el art. 1092 y en el art. 1 de la ley especial.

Vale la pena aclarar que una cosa muy distinta es cuando lo adquirido se dedica a la actividad artesanal o profesional pues, en este caso, el adquirente o usuario deviene un profano frente al proveedor, sin poder de negociación, y lo que es más grave, sin los conocimientos específicos que le permitan una adecuada tutela.

\section{4. El proveedor en los contratos de consumo}

Por otro lado, la ley individualiza al proveedor de bienes o servicios con las características específicas que determina el art. 2 de la Ley de Defensa del Consumidor, siendo la nota determinante la "profesionalidad" que debe poseer, tal como se concluyó en las XXII Jornadas de Derecho Civil, en la "Comisión de Derecho Interdisciplinario: Derecho del Consumidor" llevadas a cabo en Córdoba, en $2009^{24}$.

\footnotetext{
${ }^{23}$ STIGLITZ, R., ob. cit.

${ }^{24}$ Conclusiones disponibles en: http://www.cfna.org.ar/documentacion/jornadas-nacionales-de-derecho-civil/XXII-jornadasnacionales-de-derecho-civil-2009.pdf
} 
Así, la norma citada expresa que proveedor es la "persona física o jurídica de naturaleza pública o privada, que desarrolla de manera profesional, aún ocasionalmente, actividades de producción, montaje, creación, construcción, transformación, importación, distribución y comercialización de bienes o servicios".

En esta línea, Farina ${ }^{25}$ entiende que la noción de proveedor, es propia del derecho de consumidor, y consecuentemente, hace referencia al sector oferente de productos y servicios en la medida que se realice profesionalmente, e por ello, incluye a todos los sujetos que actúan del lado de la oferta.

Por su parte, Lorenzetti ${ }^{26}$ destaca que el origen del concepto de proveedor es característico del derecho del consumidor y recuerda que, en rigor, en el derecho privado se han usado términos más específicos como el de comerciante, asegurador, y otros, pero la categoría "proveedor" alude a todo el sector oferente de productos o servicios siempre que lo haga de una manera profesional, y en una relación de consumo.

En este sentido, las condiciones de atención y trato al consumidor y usuario, como persona humana, deben ser equitativas, es decir, no discriminatorias ni arbitrarias.

Este último aspecto apunta al aspecto meramente objetivo, la equidad importa precisamente una igualdad concreta, proporcionalidad y reciprocidad ${ }^{27}$.

\section{5. Interpretación y prelación normativa: "in dubio pro consumidor"}

En esta inteligencia, los arts. 1094 y 1095 instituyen el criterio de interpretación y de prelación normativa disponiendo que las normas deben ser aplicadas conforme al principio "in dubio pro consumidor".

En este sentido, el primero de los artículos establece claramente que las relaciones de consumo no sólo deben tutelar al consumidor, sino que deben asegurar el acceso al consumo sustentable, y por ello, en caso de duda, el contrato se interpreta en el sentido más favorable al consumidor, tal como lo dispone el art. 1095.

En esta línea, los artículos citados incorporan al Código, integrando el "núcleo duro" del plexo consumeril, el principio "in dubio pro consumidor" ya receptado por la ley 24.240 en el art. 3 .

Así, el legislador ha recurrido, en pos de tutelar al consumidor en sus relaciones contractuales, a una moderna aplicación de la llamada regla "favor debitoris".

En esta línea, Tinti y Calderón ${ }^{28}$ explican que el principio tiene nacimiento en el derecho romano, y que se encuentran textos de Ulpiano y Paulo, en los que se hace aplicación práctica

\footnotetext{
${ }^{25}$ FARINA, Juan, Defensa del Consumidor y del Usuario, Segunda Edición, Buenos Aires, Astrea, 2000, pág. 72.

${ }^{26}$ LORENZETTI, Ricardo Luis, Tratado de los contratos, Tomo 1, Santa Fe, Rubinzal Culzoni, 2004, pág. 156.

${ }^{27}$ GARDELLA, L., La equidad en el derecho del consumo, JA 2000-II-831.

${ }^{28}$ TINTI, Guillermo, CALDERÓN, Maximiliano, Derecho del Consumidor, Ley 24.240, 3ra Edición actualizada, Alveroni, Córdoba, 2011, pág. 39.
} 
del "favor debitoris".

Así, señalan que el actual Código Civil refleja este principio en los arts. 618 y 747 cuando fijan como lugar de pago el domicilio del deudor, en el art. 773 que faculta a realizar la imputación de pago al deudor, y otros dispositivos similares.

Por su parte, el Código de Comercio lo regla específicamente entre las pautas de interpretaciones contenidas en el art. 218, en torno a las cláusulas equivocas o ambiguas, y específicamente, en los casos dudosos dispone que deben interpretarse siempre en favor del deudor.

\section{6. El deber de información, la publicidad y trato digno}

Desde otro costado, también se establecen, en los arts. 1100 a 1103, las obligaciones del proveedor de suministrar información al consumidor en forma cierta y detallada, respecto de todo lo relacionado con las características de los bienes y servicios que provee, como así también, las condiciones de su comercialización. La norma destaca que la información debe ser gratuita y proporcionada con claridad.

En esta inteligencia, desde el punto de vista normativo, la información es el deber jurídico obligacional, de causa diversa, que incumbe al poseedor de la información vinculada con una relación jurídica o con la cosa involucrada en la prestación, o atinente a actividades susceptibles de causar daños a terceros, o a uno de los contratantes, derivados de dicha información, y cuyo contenido es el de poner en conocimiento de la otra parte, una cantidad de datos suficientes como para evitar los daños o inferioridad negocial que pueda generarse si no son suministrados.

Por su parte, Farina ${ }^{29}$ considera que este derecho a la debida información y su correlativo deber impuesto al proveedor tiene carácter de principio general del derecho del consumidor, como lo consagra el art. 42 de la Constitución Nacional.

En esta inteligencia, la información tiene una doble vertiente, pues por un lado es un derecho esencial de los consumidores y usuarios, y por el otro, constituye una obligación para el proveedor u oferente de los bienes o servicios.

Desde otro costado, el deber de información se complementa con la regulación referida a la publicidad, y concretamente en el art. 1101 se prohíbe toda la que contenga indicaciones falsas o que induzcan al error o que impliquen comportarse en forma perjudicial tanto para la salud como para la seguridad del consumidor.

Además, el art. 1103 regula los efectos de la publicidad, al disponer que las precisiones formuladas en tal oportunidad se tienen por incluidas en el contrato.

Desde esta perspectiva, se reglan también los contratos celebrados a distancia y se establece que las ofertas por medios electrónicos deben tener como lugar de cumplimiento aquel en el que el consumidor recibió o debió recibir la prestación.

${ }^{29}$ FARINA, J. M., ob. cit., pág. 161. 


\section{7. La facultad de revocar el contrato}

En esta línea, al reglar los contratos celebrados fuera de los establecimientos comerciales, y los contratos celebrados a distancia, el art. 1110 puntualiza que el consumidor tiene el derecho irrenunciable de revocar la aceptación dentro de los 10 días computados a partir de la celebración del contrato.

Esta facultad que el Código Civil y Comercial concede al consumidor es tan relevante que el último párrafo del artículo citado precedentemente, estipula que las cláusulas, pactos o cualquier modalidad aceptada por el consumidor durante este período que tengan por resultado la imposibilidad de ejercer el derecho de revocación, se tienen por no escritos.

Así, el art. 1111 estipula que el proveedor debe informar al consumidor sobre la facultad de revocación mediante inclusión en caracteres destacados en todo documento que presenta al consumidor en la etapa de negociaciones, o en el documento que instrumente el contrato definitivo, ubicada como disposición inmediatamente antes de la firma.

A todo evento, el precepto establece que el derecho de revocación no se extingue si el consumidor no ha sido informado adecuadamente.

Por su parte, el art. 1112 dispone que la revocación debe ser notificada al proveedor por escrito o medios electrónicos o similares, o mediante la devolución de la cosa, dentro del plazo de 10 días computado según el art. 1110.

Finalmente, tal como lo dispone el art. 1113 de la nueva compilación, la revocación tiene efecto retroactivo, y las partes quedan liberadas de sus obligaciones correspectivas, y deben restituirse recíproca y simultáneamente las prestaciones que se hayan cumplido.

\section{8. Cláusulas abusivas}

Por último al igual que en los contratos de adhesión se regulan las cláusulas abusivas, tornándose aplicables los arts. 986/987 y 988, y se establece que las cláusulas incorporadas a un contrato de consumo, pueden ser declaradas abusivas aunque sean aprobadas expresamente por el consumidor.

En esta línea, se destaca que es abusiva la cláusula que, habiendo sido o no negociada individualmente, tiene por objeto provocar un desequilibrio significativo entre los deberes y derechos de las partes, en perjuicio del consumidor.

En igual línea de pensamiento, el art. 1120 considera que existe una "situación jurídica abusiva" cuando el mismo resulta se alcanza mediante una pluralidad de actos jurídicos conexos.

Por último, en el art. 1122 se establece expresamente el control judicial de las cláusulas abusivas, autorizando al juez a declarar la nulidad parcial del contrato, y simultáneamente a integrarlo.

En este último caso, el inc. d de la norma citada, estipula que cuando se prueba una situación jurídica abusiva deriva del contratos conexos, el juez debe aplicar el art. 1075, es decir, que debe atribuírseles el sentido que surge del grupo de contratos, pero que alguno de los 
contratantes puede oponer las excepciones de incumplimiento total, parcial o defectuoso, aún frente a la inejecución de obligaciones ajenas a su contrato.

Dicho derechamente, cada supuesto de conexidad exigirá analizar cada una de las relaciones para poder resolver en consecuencia, siempre teniendo presente el principio de tutela del consumidor.

\section{DIRECTIVAS DE INTEGRACIÓN}

\section{1. La prelación normativa en el ámbito contractual}

Desde esta perspectiva, y tal como lo señalamos supra, la categoría de los contratos de consumo establece las directivas fundantes de los mínimos no disponibles de las partes y que debe articularse con la Constitución Nacional y la Ley 24.240.

En esta inteligencia, el art. 963 del Código Civil y Comercial establece un orden de prelación normativa en materia de contratos, tal como se sigue:

$1^{\circ}$ ) normas indisponibles de la ley especial y de este Código, sin prelación entre ellas como se hace entre las supletorias,

$2^{\circ}$ ) normas particulares del contrato,

$3^{\text {) }}$ normas supletorias de la ley especial;

$4^{\circ}$ ) normas supletorias de este Código.

Este orden tiene especial relevancia cuando se trate de interpretar e integrar el contrato en cada caso concreto que se plantee.

\section{2. La prelación en materia consumeril}

De igual modo, tal como se desprende de los "Fundamentos del Código Civil y Comercial del Código", los efectos de la incorporación de los principios generales en materia consumeril son:

a) No hay obstáculo para que una regulación especial establezca condiciones superiores;

b) Ninguna ley especial puede derogar estos mínimos que son un "núcleo duro" de tutela;

c) Hace a la coherencia del sistema;

d) En cuanto a la integración, habrá un diálogo de fuentes, en el que el Código recupera la centralidad para iluminar el resto de las fuentes.

Así, se estipula que la integración del sistema legal, en una escala de graduación queda compuesto por:

1) Los derechos fundamentales del consumidor reconocidos en la Constitución Nacional;

2) Los principios y reglas de protección mínima y lenguaje común del Código Civil y Comercial; y 
3) La reglamentación detallada de los derechos del consumidor vertidos en la ley 24.240.

Una vez finalizada la delimitación tripartita de los tres tipos de contratos que regla el nuevo código se advierte que el proveedor, engloba la figura del empresario y del comerciante y en la economía de mercado se encuentra inmerso en los contratos de adhesión y en los de consumo.

La afirmación precedente permite afirmar que estatuto del proveedor hace al quehacer comercial y se introduce en la jurisdicción mercantil, pero la normativa aplicable debe otorgar prevalencia a la ley de defensa del consumidor y a los principios constitucionalizados que conllevan la defensa de la dignidad humana, arts. 42 y 43 de la Carta Magna.

Ahora bien, el ámbito de la comercialidad se despliega en los contratos particulares y especialmente en la nueva economía de mercado.

\section{CONCLUSIÓN}

De tal modo, la nueva regulación de los contratos parte de una teoría general, permite distinguir entre el contrato paritario, el de adhesión y el de consumo, los que forman parte de aquella, pero se caracterizan, ya sea por la igualdad en el poder de negociación, por el modo de redacción en formularios como son los predispuestos, y por último, por el acto de consumo que implica la debilidad estructural de los negocios en masa.

En esta inteligencia, la constitucionalización del Derecho Privado, la vigencia de los derechos humanos y la nueva modalidad de las relaciones contractuales tiene una clara recepción en la diferenciación que incorpora el nuevo Código.

En una palabra, la nueva inteligencia de la Teoría General del Contrato y su fragmentación según el tipo de formulación y contratación, se adecuan a las nuevas realidades de la economía de mercado.

\section{REFERENCIAS BIBLIOGRÀFICAS}

Aparicio, Juan Manuel, Contratos en general, Observaciones al Código Civil y Código, La Ley, 5/12/2012.

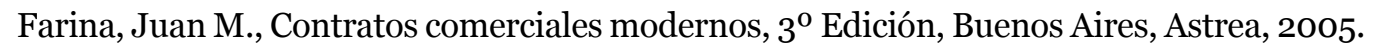

Farina, Juan M, Defensa del consumidor y del usuario, 4ta edición, 2da, reimpresión, Buenos Aires, Astrea, 2012. 
Gardella, L., La equidad en el derecho del consumo, JA 2000-II-831.

Gastaldi, José M., GASTALDI, José M., Comentarios al Código Civil y Comercial de Código Civil y Comercial de la Nación, Director: Julio César Rivera, Buenos Aires, Abeledo Perrot, 2012.

Kemelmajer de Carlucci, Aída, Conferencia dictada en la Carrera de Negocios de la UNC, $28 / 7 / 12$.

Lorenzetti, Ricardo L., Contratos modernos: ¿conceptos modernos? Nuevos aspectos de la teoría del tipo contractual mínimo. Problemas contractuales típicos. Finalidad supracontractual y conexidad, La Ley, 1996-E, 851.

Lorenzetti, Ricardo L., Tratado de los contratos, Tomo 1, Santa Fe, Rubinzal Culzoni, 2004.

Mosset Iturraspe, Jorge, Contratos, Santa Fe, Rubinzal Culzoni, 1995.

Spota, Alberto, Instituciones de Derecho Civil, vol. 1, Contratos, Buenos Aires, Depalma, 1996.

Stiglitz, Rubén, La teoría del contrato en el Código Civil y en el Proyecto de Código Civil y Comercial de la Nación, La Ley 13/o6/2012.

Tinti, Guillermo, Calderón, Maximiliano, Derecho del Consumidor, Ley 24.240, 3ra Edición actualizada, Córdoba, Alveroni, 2011.

\section{CURRICULUM VITAE}

\section{Francisco Junyent Bas}

Doctor Honoris Causa de la Universidad San Pablo Tucumán, con tesis sobre "La homologación judicial le otorga al convenio de mayorías el rango de concordato", según resolución $\mathrm{N}^{\circ}$ 463/20012. Doctor en Derecho y Ciencias Sociales de la Universidad Nacional de Córdoba, con tesis sobresaliente sobre Responsabilidad civil de los administradores societarios, 1995. Profesor Titular Plenario de Derecho Concursal en la Universidad Nacional de Córdoba, desde 1996. Profesor de Posgrado de diversas universidades del país. Premio Academia Nacional de Derecho de Córdoba 1998. Distinción académica "Ut portet nomen meun coram gentibus", Facultad de Derecho de la Universidad Nacional de Córdoba. Autor de 25 libros de la especia- 
lidad, entre otros, La ley de Concursos comentada, El salvataje de las Entidades Deportivas, ley 25284, Facultades del Juez concursal y Sistema de Ineficacia concursal en coautoría con Carlos Molina Sandoval, Responsabilidad de Administradores Societarios, Responsabilidad de Terceros en la quiebra, Responsabilidad por Fraude Laboral, Las Relaciones laborales ante el concurso y la quiebra, Acuerdo Preventivo Extrajudicial en coautoría con Mauricio Boretto, El salvataje o Cramdown en la ley 25589 en coautoría con Eduardo Chiavassa, Sociedad y Empresa: Las reglas del buen gobierno, La tutela de la Vivienda única, entre otros. Autor de más de 300 artículos en diversas revistas especializadas. Disertante en más de 350 Conferencias en diversas universidades e instituciones jurídicas. Ex Juez Concursal de la Ciudad de Córdoba a partir de 1984. Actual Fiscal de Cámara Civil y Comercial, a partir de 1989.

Director del Instituto de Estudios de la Magistratura de la Asociación de Magistrados de Provincia de Córdoba. Presidente Honorario de la Fundación para el Estudio del Derecho Concursal y la Empresa en Crisis, Pablo Van Nieuwenhove, Tucumán. Ex Director del Departamento de Derecho Comercial Facultad de Derecho Universidad Nacional de Córdoba. Profesor Honorario de la Universidad Aconcagua, Mendoza. Director del Semanario Jurídico de Comercio y Justicia. Investigador Categoría 1 por la CONEAU en el ámbito universitario.

fjunyentbas@gmail.com

\section{María Constanza Garzino}

Doctorando en Derecho. Universidad Pompeu Fabra. Barcelona. España, apto: Enero de 2016. Magíster en Derecho Privado. Universidad Nacional de Rosario.

Abogada. Universidad Nacional de Córdoba. Diplomada en Derecho del Consumidor.

UNC. Posgrado en Formación Superior en Daños. UCC. Coautora de la Ley de Defensa del Consumidor, Concordada, comentada y anotada de ERREPAR, junto con Junyent Bas, Francisco, Molina Sandoval, Carlos, Heredia Querro, Sebastián. Autora de numerosos artículos especializados en derecho civil y derecho del consumidor, en libros y revistas especializadas, y de diversos comentarios al texto del nuevo Código Civil y Comercial en materia de obligaciones, contratos y derecho del consumidor en Códigos Comentados y Libros. Docente de Derecho Privado II. UNC. Suplente. 2016. Docente Derecho Privado II. Universidad Siglo 21. Por concurso. 2012 a la actualidad. Integrante del equipo de investigación sobre el tema: "DEBERES SECUNDARIOS DE CONDUCTA EN EL DERECHO CIVIL, COMERCIAL Y DEL CONSUMIDOR”, Categoría “B”, Director: Andrés Federico Varizat, aprobado por RESOLUCION SECyT $\mathrm{N}^{\circ}:$ 203/2014. Desempeño profesional como “Auxiliar" en el Poder Judicial de la Provincia de Córdoba, desde 2008 hasta la actualidad. Fiscalía de Cámaras Civil, Comercial y Laboral, con función de "Asistente de magistrado" del Fiscal de Cámaras en lo Civil, Comercial y Laboral. Disertante, coordinadora, ponente y asistente a diversos cursos de posgrado, jornadas y simposios de derecho privado.

cotigarzino@gmail.com 